\title{
ARECA NUT USE IN RURAL TAMIL NADU: A GROWING THREAT
}

\author{
GUNASEELAN RAJAN, SOWMYA RAMESH, SHANTHI SANKARALINGAM
}

\section{ABSTRACT}

BACKGROUND: Areca nut is the fourth main psychoactive substance in the world. In India, tobacco is added to the quid, and the commercially manufactured nonperishable forms of betel quid (pan masala or gutkha) are on the rise in the market. OBJ ECTIVE: To find out the prevalence of areca nut among the rural residents of Sriperambudur Taluk. SETINGS AND DESIGN: A community-based survey using pre-tested semi-structured questionnaire. MATERIALS AND METHODS: The survey was conducted in 2 villages and their colonies, which were randomly selected out of 168 villages. Data was collected from 500 residents of the study population. The survey was conducted for a period of 2 months. STATISTICAL ANALYSIS: SPSS version 10.0. RESULTS: The study participants were more likely to initiate areca nut use by 22 years of age. As many as $19.8 \%$ ( $n=$ 99) of the study participants chewed areca nut products, out of whom $11.2 \%$ ( $n=56$ ) indulged in chewing habit alone (areca nut products). Areca nut use was higher among male study subjects compared to females. The commercial forms of areca nut products (gutkha) were the most prevalent ones [47.5\% $(n=47)$ of those who used areca nut] observed in the community. Compared to female participants, male participants were more likely to perceive areca nut use as the most harmful habit draining the community health and wealth. CONCLUSION: There seems to be an increase in the prevalence of areca nut use. The community also perceives it to be a harmful habit. Therefore, effective interventions should be targeted towards the high-risk subpopulation of the community to decrease the prevalence of areca nut use in rural Tamil $\mathrm{Nadu}$.

Key words: Areca nut, community-based survey, gutkha, high risk, pan masala, prevalence; rural community

Areca nut plays an integral part in religious ! functions in India. Areca nut is available in ! processed and unprocessed forms. The ! processed forms are available with (gutkha) and! without tobacco (plain pan masala). Areca nut! is taken as it is or wrapped in a betel leaf along !

Chennai Dental Research Foundation, !

Dr. Radhakrishnan Salai, Mylapore, Chennai, India!

\section{Correspondence:}

Ms. Shanthi Sankaralingam,!

Chennai Dental Research Foundation, Dr. Radhakrishnan!

Salai, Mylapore, Chennai - 600 004, India.

E-mail: shanthi_srk@yahoo.com! with slaked lime and condiments (betel quid).

Studies have also linked betel chewing ! with increased risk of several other medical ! conditions, including heart disease, diabetes ! and asthma. Of greatest concern, however, is a ! condition called oral submucous fibrosis, which! frequently leads to mouth cancer. In some study ! populations, nearly $90 \%$ of the people with this ! condition were habitual betel chewers. ${ }^{[1] !}$

Chewing betel quid has been positively ! 
associated with oral lesions, which has the potential for malignant transformation. ${ }^{[2-6]}$

There is a need to decrease areca nut use. Therefore, a community-based survey was ! conducted to understand the prevalence in ! order to implement interventions.

\section{MATERIALS AND METHODS}

A community-based survey was conducted in two of the villages of Sriperambudur Taluk. Two villages and their colonies were randomly ! selected out of 168 villages of Sriperambudur ! Taluk. Random sampling method was used! for the survey. Five hundred residents of the ! selected villages who were above 15 years! of age were included in the study. Ethical ! clearance was obtained from the local review ! board. A written consent was obtained from ! the study participants before recruiting them ! into the study. Data was collected using a pre-tested semi-structured questionnaire, and ! interview lasted for about $20 \mathrm{~min}$. The study was conducted for a period of 2 months - from ! the first week of February 2006 to the first week ! of April 2006. The statistical analysis was done ! using SPSS version 10.0

\section{RESULTS}

\section{Profile of the study subjects}

Table 1 shows the distribution of study subjects ! by basic characteristics. The number of males ! was almost equal to the number of females ! in the study population $[51.8 \%(n=259)$ and ! $48.2 \%(n=241)$ respectively]. As many as ! $34.6 \%(n=173)$ of the study participants were ! in the age group of $15-25$ years, $26 \%(n=130)$ ! were in the age group of $26-35$ years, $15.6 \%$ !
( $n=78)$ were in the age group of 36-45 years, ! $11.8 \%(n=59)$ were in the age group of $46-55$ ! years and the remaining $12 \%(n=60)$ were ! above 56 years.

\section{Prevalence of chewing by basic characteristics}

As many as $19.8 \%(n=99)$ of the study ! participants chewed areca nut products, out of ! whom about $11.2 \%(n=56)$ indulged in chewing ! habit alone (areca nut products); whereas about ! $8.6 \%(n=43)$ of them had multiple habits, as can ! be seen in Graph 1. The prevalence of chewing ! areca nut products was higher among male study ! subjects compared to females $(P=0.001)$.

About $25.5 \%(n=66)$ of the male study ! participants indulged in chewing areca nut! products, whereas only $14 \%(n=33)$ of females ! indulged in the chewing habit. We did not! observe a statistically significant lassociation! between chewing habit and education level $(P$ ! $=0.98)$, family income $(P=0.67)$, occupation ! $(P=0.36)$ and village of residence $(P=0.19)$ ! of the study participants. Although we did not ! find a significant association between education! and chewing habit, yet we did observe that !

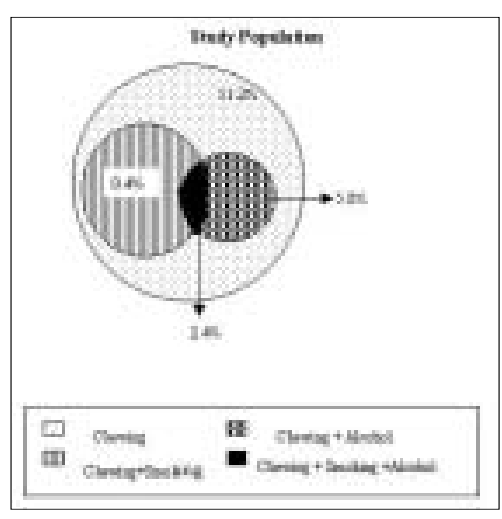

Graph 1: Venn diagram of the prevalence of ! combination of habits among study participants! the prevalence of chewing areca nut products ! decreased with literacy level. The results are ! presented in Table 2.

The age at which the study subjects started ! chewing areca nut products ranged from a ! minimum of 12 years to a maximum of 70 years ! with the median age being 22 years (Graph ! $2)$. About $58 \%(n=57)$ of the study subjects ! who indulged in the chewing habit (areca nut! products) chewed more than twice a day, and ! about $68.7 \%(n=68)$ of the study subjects ! chewed less than or equal to one pack of pan masala or gutkha or one set of betel quid per! day. Other than the frequency and quantity of ! chewing product, the amount of time it is kept ! in the mouth also plays an important role in ! affecting the oral mucosa. About $84 \%(n=83)$ !

Table 1: Distribution of the study participants by basic characteristics

\begin{tabular}{|c|c|c|c|}
\hline Characteristics & Male (\%) & Femalt & \\
\hline Age group $(n=500)$ & & & \\
\hline
\end{tabular}

$\begin{array}{llll}15-25 ! & 88(50.9) ! & 85(49.1) ! & 173(34.6) ! \\ 16-35 ! & 60(46,2) ! & 70(59.8) ! & 130(26.0) !\end{array}$ $\begin{array}{llll}16-35 ! & 60(46.2) ! & 70(59.8) ! & 130(26.0) ! \\ 36-45 ! & 48(61.5) ! & 30(38.5) ! & 78(15.6) !\end{array}$ $\begin{array}{llll}36-45 ! & 48(61.5) ! & 30(38.5) ! & 78(15.6) ! \\ 46-55 ! & 27(45.8) ! & 32(54.2) ! & 59(11.8) !\end{array}$ $\begin{array}{llll}46-55 ! & 27(45.8) ! & 32(54.2) ! & 59(11.8) ! \\ >55 ! & 36(60.0) ! & 24(40.0) ! & 60(12.0) !\end{array}$ Education $\begin{array}{lllll}\text { Education! } & 109(41.4) ! & 154(58.6) ! & 263(52.7) ! \\ \text { Illiterate ! } & 57(56.4) ! & 44(43.6) ! & 101(20.2) ! \\ 1^{\text {st }-5 \text { th }} & & 54(66) & 37(33.3) ! & 11(22.2) !\end{array}$ $6^{\text {th }-10^{\text {th } 1}} \quad 74(66.7) ! 37(33.3) ! 111(22.2) !$ $11^{\text {th }}$ and $12^{\text {th }} \div 17(81.0) ! 4(19.0) ! 21(4.2) !$ $\begin{array}{llll}\text { Above } 12^{\text {th }} & 1(33.3) & 2(66.7) & 3(0.6) ! \\ \text { Family income! }\end{array}$ $\begin{array}{llll}\begin{array}{l}\text { Family income! } \\ \text { <Rs. 500! }\end{array} & 36(55.4) ! & 29(44.6) ! & 65(13.0) ! \\ \text { Rs. 500-Rs.1000! } & 122(50.6) ! & 119(49.4) ! & 241(48.2) !\end{array}$ $\begin{array}{lllll}\text { Rs. 500-Rs. } 1000 ! & 122(50.6) ! & 119(49.4) ! & 241(48.2) ! \\ >\text { Rs. } 1000 ! & 100(53.2) ! & 88(46.8) ! & 188(37.6) !\end{array}$ $\begin{array}{llll}\text { PRs. } 1000 ! & 100(53.2) ! & 88(46.8) ! & 188(37.6) ! \\ \text { No income ! } & 1(16.7) ! & 5(83.3) ! & 6(1.2) !\end{array}$ Occupation! $\begin{array}{llll}\text { Embroidery ! } & 180(63.8) ! & 102(36.2) ! & 282(56.4) ! \\ \text { Agriculture ! } & 33(64.7) ! & 18(35.3) ! & 51(10.2) !\end{array}$ $\begin{array}{llll}\text { Agriculture! } & 33(64.7) ! & 18(35.3) ! & 51(10.2) !\end{array}$ $\begin{array}{lccc}\text { Company } & 2(100) & 0 & 2(0.4) ! \\ \text { Unemployed! } & 31(20.9) ! & 117(79.1) ! & 148(29.6) !\end{array}$ $\begin{array}{lccc}\text { Unemployed! } & 31(20.9) ! & 117(79.1) ! & 148(29.6) ! \\ \text { Others! } & 13(5.0) ! & 4(23.5) ! & 17(3.4) ! \\ \text { Village! } & & & \end{array}$

TMK main village ! $61(59.2) !$
TMage $\begin{array}{llll}\text { TMK old colony ! } & 47(49.0) ! & 49(51.1) ! & 96(19.2) ! \\ \text { TMK new colony ! } & 46(51.1) ! & 44(48.9) ! & 90(18.0) !\end{array}$ AMK new colony! \begin{tabular}{llll} 
Village ! & $59(49.2) !$ & $61(50.8) !$ & $120(24.0) !$ \\
Agaram colony ! & $46(50.5) !$ & $45(49.5) !$ & $91(18.2) !$ \\
\hline
\end{tabular} of the study subjects who had the chewing habit ! (areca nut products) kept the product for more ! than $5 \mathrm{~min}$ in the mouth. The amount spent by ! the rural residents on chewing products varied! from Rs. 3 to more than Rs. 6 per day, with ! about $70.7 \%(n=70)$ of them spending more! than Rs. 3 per day.

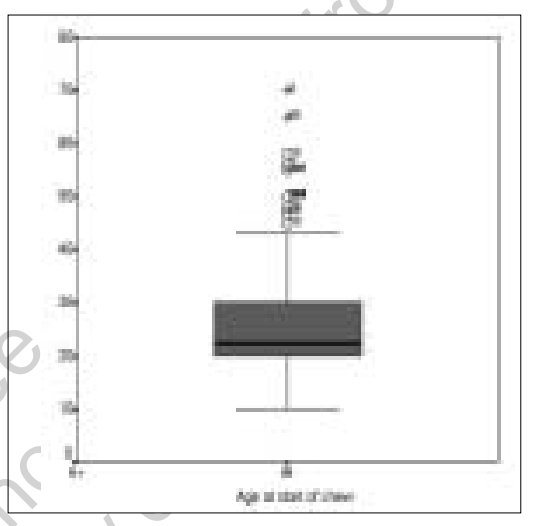

Graph 2: Box plot of age at starting of alcohol! Consumption among those who chew arecanut! products!

Table 2: Prevalence of chewing areca nut products by basic characteristics

\begin{tabular}{|c|c|c|c|}
\hline Characteristics & $\begin{array}{l}\text { Chew areca } \\
\text { nut product } \\
\text { (\%) }\end{array}$ & $\begin{array}{l}\text { Don't chew } \\
\text { areca nut } \\
\text { product (\%) }\end{array}$ & $P$-value \\
\hline \multicolumn{4}{|l|}{ Education $(n=500) !$} \\
\hline & $53(53.5)$ & $210(52.5)$ & $0.98 !$ \\
\hline $1^{\text {st }-5^{\text {th }}}$ & 20 (20.2)! & $81(20.3) !$ & \\
\hline $6^{\text {th }}-10^{\text {th! }}$ & 23 (23.2)! & $88(22.0) !$ & \\
\hline $11^{\text {th }}$ and $12^{\text {th! }}$ & $3(3.0) !$ & $18(4.5) !$ & \\
\hline \multirow{2}{*}{\multicolumn{4}{|c|}{ Family Income! }} \\
\hline & & & \\
\hline & $12(12.1) !$ & $53(13.2$ & 0.67 \\
\hline Rs. 500 -Rs. 1000 ! & 45 (45.5)! & $196(48.9) !$ & \\
\hline$>$ Rs. 1000 ! & $40(40.4) !$ & 148 (36.9)! & \\
\hline No income! & $2(2.0) !$ & $4(1.0) !$ & \\
\hline \multicolumn{4}{|l|}{ Occupation! } \\
\hline Embroidery & $55(55.6)$ & 227 (56.6) & 0.36 \\
\hline & $14(1$ & 37( & \\
\hline Company! & $0(0) !$ & 2 (0.5) & \\
\hline Unemployed & $25(25.3)$ & $123(30.7)$ & \\
\hline & $5(5.1)$ & $12(3.0)$ & \\
\hline \multicolumn{4}{|l|}{ Village } \\
\hline TMK main vill & $29(29.3)$ ! & $74(18.5) !$ & 0.19 \\
\hline TMK old co & & $81(20.2)$ & \\
\hline TMK new colony! & 18 (18.2)! & $72(18.0) !$ & \\
\hline Agaram main village ! & $20(20.2) !$ & 100 (24.9)! & \\
\hline Agaram colony! & $17(17.2) !$ & $74(18.5) !$ & \\
\hline
\end{tabular}


Prevalence of chewing habit by age group The prevalence of chewing areca nut products ! was highest among those above 55 years of age. As many as $47.5 \%(n=47)$ of the study participants who indulged in chewing areca nut products chewed Hans (gutkha), whereas ! $27.5 \%(n=27)$ of them chewed unprocessed form of areca nut (Kottai pakku). We observed! from our study that chewing Hans was the most common form among those between 15 ! and 25 years of age when compared to other age groups. However, chewing unprocessed! form was the most prevalent among those participants above 55 years of age. We observed an increasing trend in the use of unprocessed form of areca nut with every ! decade of life; but in case of Hans use, it was! the reverse, as can be seen in Graph 3.

\section{Reasons for indulging in chewing areca} nut products

'Time pass' colloquial for using time for irrelevant activity during work, frustration and! tension due to family problems, digestion of ! food and as a treatment for toothache were the ! main reasons given by the study participants ! for getting into the chewing habit (Graph 4). As many as $96 \%(n=95)$ of the study subjects ! reported that chewing areca nut made them ! feel good, relaxed, elated or high.

\section{General awareness}

\section{Perception of the most harmful habit}

Compared to females, males were more ! likely to perceive chewing areca nut as the ! most harmful habit. Among female study ! participants, more than $72 \%(n=174)$ of them ! reported consumption of alcoholic beverages ! alone to be the most harmful habit draining the ! community's health and wealth when compared! to the other habits prevalent in the community, ! such as chewing areca nut products and! smoking, irrespective of their personal chewing! habit. Among the male study participants ! also, consumption of alcoholic beverages ! was considered to be the most harmful habit ! [54.5\% $(n=36)$ of those who chewed areca nut ! products, $44.6 \%(n=86)$ of those who did not ! indulge in chewing areca nut products]. The ! results are presented in Graph 5.

\section{Knowledge about ingredients, benefits} and harmful health effects of areca nut products

More than $97 \%(n=487)$ of the study ! participants were not aware of the ingredients ! of the chewing product, irrespective of ! their personal chewing habit. About $7 \%$ of !

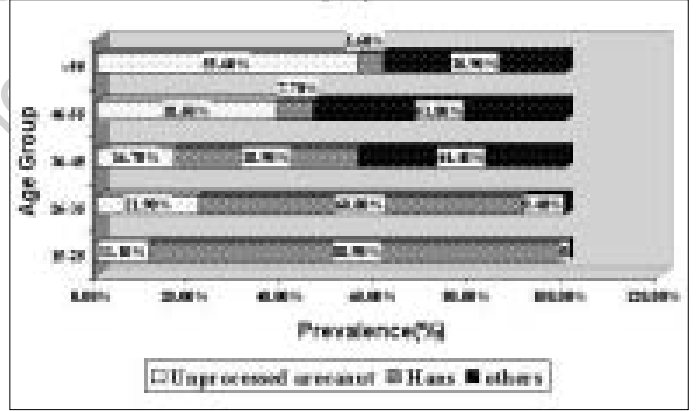

Graph 3: Prevalence of diferent types of arecanut ! products by age group!

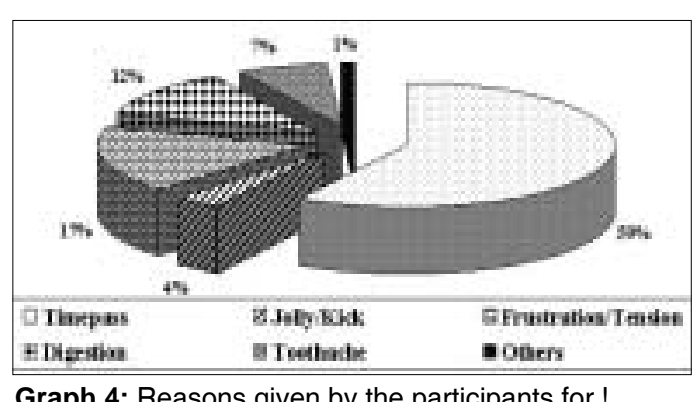

Graph 4: Reasons given by the participants for !

chewing areca nut products!

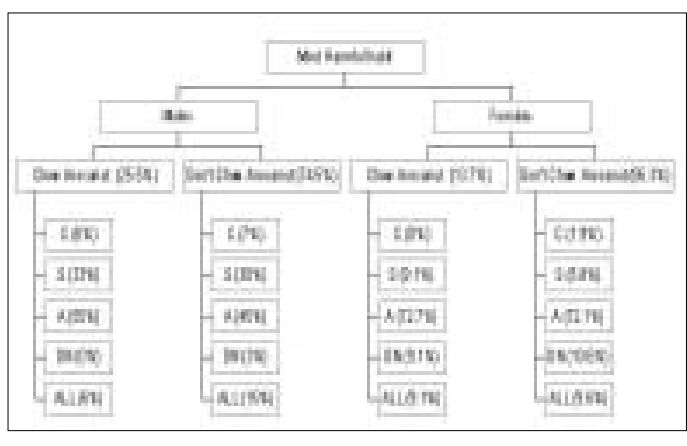

Graph 5: Organization chart showing the perception! of the study participants about the most harmful habit ! in the community. C: Perceives chewing as the most ! harmful habit, S: Perceives smoking as the most! harmful habit, A: Perceives alcohol as the most harmful! habit, DN: Don't know, ALL: Perceives all the three ! habits as the most harmful habit.

the study participants felt that chewing or application of the product over gums or teeth ! was beneficial; they got relief from pain.! There was a statistically significant !difference! in the knowledge about health effects due to chewing habit between those who chewed! areca nut products and those who did not $(P$ ! $=0.001)$. As many as $58 \%(n=99)$ of those who had the chewing habit (areca nut) were! not aware of the ill effects of chewing areca nut products on health, whereas $35 \%(n=401)$ ! of the nonchewers (areca nut products) were ! unaware of the ill effects. Among those who did ! not chew (areca nut), $43 \%(n=174)$ of them ! perceived chewing areca nut products would ! lead to some health problem, although they ! were not aware of the type of health problem; ! whereas only $26 \%(n=26)$ of those who had! the chewing habit (areca nut) reported of being ! aware of the type of health problems. More than! $53 \%(n=210)$ of the study participants felt that ! once a person gets into the habit of chewing ! areca nut products, he/she would not be able ! to leave it. Health problems, family pressure, awareness and banning of the products from ! the community were some of the reasons given! by the study participants for decrease in the ! prevalence of this habit, with banning of the ! products and personal health problems being ! the two main reasons.

\section{DISCUSSION}

Community-based surveys are essential in ! estimating the prevalence of a risk factor in the ! population and in the identification of high-risk ! subpopulation. The prevalence of chewing! habit $(19.8 \%)$ in our study population was! higher when compared to the results reported! by Neufeld and his co-workers (14\%) using ! the Indian National Sample Survey data. ${ }^{[7]}$ ! Our study result regarding chewing areca! nut products being more prevalent among! males compared to females is consistent with! previously reported studies. Earlier studies have! reported that the commercial forms of areca! nut are increasingly becoming popular among ! the youth of India. ${ }^{[8-10]}$ A study conducted by! Gupta in 1996 shows that $27.1 \%$ of men chew ! betel quid with tobacco, and about $44.5 \%$ of ! women practice smokeless tobacco in the city! of Mumbai. ${ }^{[11]}$ In another study conducted by ! Gupta in 2004, shows that use of arecanut in! any form is not safe for oral health especially ! the commercially manufactured forms seems ! even more riskier. ${ }^{[12]}$ We observed from the ! data gathered from this community that there ! was an increase in the use of commercial forms ! of areca nut among the youth of rural areas of ! Tamil Nadu. Therefore, we would be seeing! an increasing trend in the burden of disease ! and health care costs due to areca nut use ! in the rural parts of Tamil Nadu. Awareness! regarding the ill health effects of areca nut! use was minimal. Therefore, there is a need! 
to improve the level of awareness among the ! rural population. Although chewing of areca nut ! may be a practice of great antiquity, it cannot ! be regarded as a safe habit. To change the ! views of people regarding high-risk behavior, all ! sectors of the community should get involved! in community-wide programs involving families, ! peers and village leaders.

It was surprising to observe that the youth ! of rural Tamil Nadu are indulging in high-risk ! behavior (chewing areca nut products with ! tobacco). More studies are needed in other! rural parts of Tamil Nadu to corroborate the ! results from our study.

\section{ACKNOWLEDGMENTS}

We thank The Kidney Help Trust and Tulsi Trust for ! allowing us to execute our study in Sriperambudur! Taluk. We are grateful to the health workers of The ! Kidney Help Trust and Tulsi Trust for giving the ! necessary help in the field. We are most grateful to! Dr. Manjula Datta, Professor and Head, Department! of Epidemiology, The Tamil Nadu Dr. MGR Medical ! University, for providing her expertise and guidance ! for successful execution of the project.

\section{REFERENCES}

1. IARC Monographs on the Evaluation of the Carcinogenic Risks of Chemicals to Humans. Betel-quid and areca-nut chewing and some! areca-nut-derived nitrosamines. IARC Press: ! Lyon, France; 2004. p. 85.

2. Maher R, Lee AJ, Warnakulasuriya KA, Lewis JA, ! Johnson NW. Role of areca nut in the causation! of oral submucous fibrosis: A case-control study ! in Pakistan. J Oral Pathol Med 1994;23:65-9.

3. !Gupta PC, Bhonsle RB, Murti PR, Daftary !
DK, Mehta FS, Pindborg JJ. An epidemiologic ! assessment of cancer risk in oral precancerous ! lesions in India with special reference to nodular ! leukoplakia. Cancer 1989;63:2247-52.

4. ! Control of oral cancer in developing countries.! A WHO meeting. Bull World Health Organ ! 1984;62:817-30.

5. ! Sankaranarayanan R, Mathew B, Varghese C, ! Sudhakaran PR, Menon V, Jayadeep A, et al. Chemoprevention of oral leukoplakia with vitamin ! A and beta carotene: An assessment. Oral Oncol! 1997;33:231-6.

6. !Murti PR, Bhonsle BB, Gupta PC, Daftary ! DK, Pindborg JJ, Mehta FS. Etiology of oral ! submucous fibrosis with special reference to the ! role of areca nut chewing. J Oral Pathol Med! 1995;24:145-52.

7. ! Neufeld KJ, Peters DH, Rani M, Bonu S, Brooner ! RK. Regular use of alcohol and tobacco in India ! and its association with age, gender and poverty. Drug Alcohol Depend 2005;77:283-91.

8. ! Gupta PC, Mehta FS, Daftary DK, Pindborg JJ, ! Bhonsle RB, Jalnawalla PN, et al. Incidence rates ! of oral cancer and natural history in a 10-year! follow up study of Indian villages. Community ! Dentist Oral Epidemiol 1980;8:287-333.

9. ! Gupta PC, Pindborg JJ, Mehta FS. Comparison ! of carcinogenicity of betel quid with and without ! tobacco. An epidemiological review. Ecol Dis ! 1982;1:213-9.

10. Reddy KS, Arora M. Tobacco use Among Children ! in India: A Burgeoning Epidemic. Indian Pediatr ! 2005;42:757-61.

11. Gupta! PC. Survey of sociodemographic ! characteristics of tobacco use among 99,598! individuals in Mumbai, India using handheld ! computers. Tob Control 1996;5:114-20.

12. Gupta PC, Ray CS. Epidemiology of betel quid ! usage. Ann Acad Med Singapore 2004;33:31-6.

Source of Support: Nil, Conflict of Interest: None declared. 